\title{
O ESTUDO DO GESTO NA ENCRUZILHADA \\ DAS PRÁTICAS E CONCEITOS: \\ APONTAMENTOS PARA A REFLEXÃO SOBRE ENCONTROS DE PESQUISADORES FRANCO- BRASILEIROS NOS COLÓQUIOS ARTES DO GESTO
}

\author{
Suzane Weber da Silva \\ Professora Adjunta do Departamento de Arte Dramática e do Programa de Pós-Graduação em Artes \\ Cênicas da Universidade Federal do Rio Grande do Sul \\ Mônica Fagundes Dantas \\ Professora Associada do Departamento de Educação Física, Fisioterapia e Dança e do Programa de \\ Pós-Graduação em Artes Cênicas da Universidade Federal do Rio Grande do Sul
}

\section{Resumo}

Este ensaio tem por propósito refletir sobre a trajetória dos encontros entre pesquisadores franco-brasileiros em torno da leitura do gesto. Descrevemos brevemente os eventos realizados em diferentes universidades brasileiras, sob o nome de Colóquios de Artes do Movimento, realizados entre 2015 e 2017 . Esboçando cartografias, destacamos os participantes e temas envolvidos nos eventos. Propomos, a partir de da escuta das impressões que esses encontros nos causaram, uma reflexão sobre algumas concepções que norteiam a leitura e análise do gesto, cotejadas à nossa própria prática como pesquisadoras e confrontadas aos conceitos de hibridação e antropofagia.

Palavras-chave

Dança. Análise do Movimento. Leitura do Gesto. Pesquisa em Artes Cênicas.
Abstract

This essay aims to reflect about the meetings between Franco-Brazilian researchers around movement and gesture analysis. We describe the events organized by different Brazilian universities, under the name of Colloquiums of Movement Arts, between 2015 and 2017. Outlining cartographies, we highlight the participants and themes involved in the events. We propose, based on listening to the impressions that these encounters have caused us, to reflect on some conceptions that guide the reading and analysis of the gesture, compared to our own practice as researchers and confronted with the concepts of hybridization and anthropophagy.

Keywords

Dance. Movement Analysis. Gesture Studies. Research in PerformingArts. 
Por ocasião da VI Reunião Científica da Associação Brasileira de Pesquisa e Pós-Graduação em Artes Cênicas (ABRACE) ocorrida em Porto Alegre em 2011, evento que congregou em torno de 400 pesquisadores, professores e alunos de diversas instituições de ensino superior do Brasil, entramos em contato com diversos pesquisadores, entre eles a pesquisadora francesae professora do Departamento de Dança da Universidade Paris 8, Dra. Christine Roquet. A partir do tema Tempos de Encontro: criação, acontecimento e pesquisa, a IV Reunião Científica ${ }^{1}$ proporcionou um grande número de debates sobre diferentes dimensões da noção de encontro no âmbito das artes cênicas. A abertura do evento contou com as palestras de doisconferencistas convidados, Prof. Dr. Jorge Dubatti (Universidad de Buenos Aires) e Prof. ${ }^{a}$ Dr. ${ }^{\text {a }}$ Christine Roquet. A palestra de Roquet intitulou-se Ao encontro da criação: a análise do movimento e o processo de criação coreográfica e contribuiu para difundir o pensamento de pesquisadores franceses sobre o estudo do gesto.

Logo após o evento realizado em Porto Alegre, Christine Roquet seguiu para a Universidade Federal do Estado do Rio de Janeiro (UNIRIO), a convite da Prof. ${ }^{a}$ Dr. ${ }^{a}$ Joana Ribeiro. Sendo assim, a partir de 2011, a vinda da pesquisadora Christine Roquet ao Brasil foi uma oportunidade de estreitaros laços de Christine junto a pesquisadores e bailarinos brasileiros, proporcionando umatroca de experiências voltada para o estudo e análise do gesto. O tema da análise do gesto e de vários conceitos que giram em torno dessa noção alimentou muitos debates, práticas, encontros, entrevistas e

1 As palestras e outros textos significativos resultantes da VI Reunião Científica da ABRACE estão disponíveis em Carreira, Torrese Bião (2012). publicações ${ }^{2}$. E suscitou o desejo de investir numa troca efetiva entre Christine Roquet e pesquisadores brasileiros.

Este ensaio tem por propósito, justamente, pensar sobre os encontros realizados a partir de então. Os eventos foram organizados sob a forma e o nome de Colóquios de Artes do Movimento. Esboçando cartografias, destacamos os participantes e temas envolvidos nos eventos que se seguiram. No intuito de "acompanhar um processo e não de representar um objeto" (Kastrup, 2015, p. 32), propomos, a partir de da escuta das impressões que esses encontros nos causaram, uma reflexão sobre alguns conceitos que norteiam a leitura e análise do gesto, cotejadas à nossa própria prática como pesquisadoras no Programa de Pós-Graduação em Artes Cênicas da UFRGS (PPGAC/UFRGS).

Trajetórias dos encontros franco-brasileiro em torno da leitura do gesto nos Colóquios Artes de Movimento

Dando continuidade aos estudos sobre gesto desde um ponto de vista de trocas franco-brasileiras, em março de 2015 Joana Ribeiro Tavares $^{3}$ reuniu um expressivo número de 
pesquisadores ${ }^{4}$ na UNIRIO para participar do I Colóquio Nacional de Artes do Movimento: $A$ análise do movimento e a pesquisa em artes, promovido pelo Programa de Pós-Graduação em Artes Cênicas da UNIRIO. O evento abrangeu o curso Abordagem Sistêmica do Gesto Expressivo e o Colóquio propriamente dito. $\mathrm{O}$ curso, ministrado por Christine Roquet e Joana Ribeiro, teve duração de 45 horas e contou com a participação das professoras doutoras Mônica Dantas (UFRGS), Suzi Weber (UFRGS) e Lenira Peral Rengel (UFBA), que colaboraram na tradução simultânea do francês para o português. O Colóquio reuniu pesquisadores que mostraram interesse em dar continuidade àleitura do gesto, relacionando-a a aspectos históricos, problemas de terminologia, propostas de grades e de ferramentas para análise do movimento. As palestras de abertura do evento foram proferidas por Christine Roquete Regina Miranda, e dando prosseguimento ao Colóquio, outros pesquisadores brasileiros tambémapresentaram suas pesquisas. Cabe ressaltar que Regina Miranda é uma importante referência no que tange aos estudos do movimento, tanto no Brasil quanto no mundo ${ }^{5}$. Regina Miranda é uma pesquisadora de visibilidade tanto no contexto de formação e produção artística quanto no contexto acadêmico. Mesmo sem titulação de doutorado, suas pesquisas e publicações são bastante respeitadas

4 Entre outros pesquisadores encontravam-se reunidos os pesquisadores Lenira Rengel (UFBA), Gustavo Cortês (UFMG), Vinicius Machado de Almeida (UFRJ), Ana Terra (UNICAMP) e Mônica Dantas e Suzi Weber (UFRGS).

5 Com formação e larga atuação no Laban-Bartenieff Institute of Movement Studies (LIMS $®$ ), no qual ocupa o cargo de Diretora de Arte e Cultura, divide-se entre Nova e Rio de Janeiro. Foi coreógrafa e diretora da Companhia Atores Bailarinos, foi diretora do Centro Coreográfico do Rio de Janeiro (2004-2008) e desde 2010 é coordenadora da pós-graduação latu sensu no Sistema Laban-Bartenieff na Faculdade Angel Vianna. Ver Miranda (1980, 2008). no meio acadêmico e sua influência é marcante, tendo formado bailarinos, pesquisadores, professores e terapeutas corporais que trabalham com análise do movimento. Ao longo das últimas décadas, isso se deve pela sua participação em cursos e palestras em festivais de artes cênicas, bem como em eventos acadêmicos e congressos nacionais e internacionais, demonstrando a força da perspectiva dos estudos de Laban ${ }^{6}$ e Laban-Bartenieff no Brasil ${ }^{7}$.

O contexto de debate proporcionado pelo Colóquio em torno do gesto significou uma oportunidade para o grupo de pesquisadores que se encontravam no evento, vindo de diferentes universidades do Brasil,de explorara leitura do gesto sob diferentes perspectivas e práticas corporais. Desse modo, ao final do evento, surgiu a ideia de promover um encontro anual desse grupo de pesquisadores, a fim de continuar os estudos sobre leitura do gesto.

Em 2016, dando continuidade ao encontro realizado no Rio de Janeiro, o Programa de Pós-Graduação em Artes Cênicas da UFRGS

\footnotetext{
6 Rudolf Laban (1879-1958), nascido em Bratislava, então pertencente ao Império Austro-Húngaro, desenvolveu seu trabalho na Alemanha e na Inglaterra. Criou um importante método para análise do movimento humano, em que espaço, tempo, peso, energia/esforço são alguns parâmetros. Desenvolveu uma concepção de espaço a partir da figura da kinesfera - esfera englobando o espaço de proximidade do corpo em movimento, cujo centro corresponde ao centro de gravidade do corpo. Criou um sistema de registro de movimento - labanotation. Desenvolveu também uma metodologia para o ensino da dança, cujo objetivo principal era preparar o corpo do bailarino para que ele pudesse responder a diferentes exigências e solicitações relativas à expressão de sentimentos, sensações e emoções. As principais instituições de disseminação das pesquisas de Laban são o Trinity Laban Conservatoire of Music and Dance (Reino Unido) e o Laban-Bartenieff Institute of Movement Studies (LIMS $®$ ) (Nova lorque). Os estudos em Laban estão presentes em instituições de vários países; na América Latina, destacam-se Brasil, Argentina e Chile.
}

7 Sistema de Análise Laban/Bartenieffem Movimento desenvolvido principalmente por Irmgard Bartenieff(1900-1981), a partir de sua colaboração com Rudolf Laban, ao longo do século XX. Ver Bartenieff e Lewis, 1997. 
promoveu o II Colóquio Internacional de Artes do Movimento: narrativas do gesto e do movimento nas Artes Cênicas ${ }^{8}$. O evento, organizado por Suzi Weber e Mônica Dantas, possibilitou a realização de trocas efetivas entre pesquisadores e estudantes de graduação e pós-graduação, enfatizando o cruzamento entre teoria e prática. A palestra de abertura foi realizada por Christine Roquet e Adriana Bonfatti ${ }^{9}$, propondo um cotejamento entre a abordagem sistêmica do gesto expressivo, tal como é praticada na Universidade de Paris 8, e a análise do movimento na perspectiva do Sistema Laban-Bartenieff, especialidade de Adriana Bonfatti. As oficinas seguiram essa proposta de integração entre diferentes perspectivas eforam ministradas por Christine Roquet, Lenira Rengel ${ }^{10}$, Joana Ribeiro Tavares, Marito Olsson-Forsberg e Adriana Bonfatti. As oficinas visaram um estudo crítico e reflexivo sobre o gesto, entrecruzando a Abordagem sistêmica do gesto expressivo, o Sistema Laban-Bartenieff, os temas de movimento de Rudolf Laban (ver Rengel, 2008) e as abordagens

8 O evento foi realizado de 12 a 15 de abril de 2016, promovido pelo PPGAC/UFRGS em parceria com os cursos de Graduação em Teatro e de Dança da UFRGS, bem como do coletivo Sala 209 Usina das Artes. Os professores convidados do evento foram Prof. ${ }^{a}$ Ms. Adriana Bonffati (UNIRIO), Prof. ${ }^{a}$

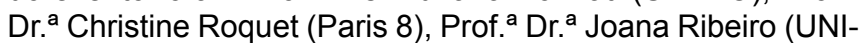
RIO), Prof. ${ }^{a}$ Dr. ${ }^{a}$ Lenira Rengel (UFBA) e Prof. Ms. Marito Olsson-Forsberg (Faculdade Angel Viana). Também participaram as pesquisadoras e doutorandas Sandra Santana (UFBA) e Caroline Maria Holanda Cavalcante (Universidade Federal do Ceará/UFC)

9 Adriana Bonfatti é mestre em Artes Cênicas pela Universidade Federal do Estado do Rio de Janeiro-UNIRIO. É analista Laban de Movimento (CMA) pelo Laban/Bartenieff Institute of Movement Studies e Professora do Departamento de Interpretação do curso de Atuação Cênica da UNIRIO.

10 Professora Doutora da Escola de Dança da Universidade Federal da Bahia. Aborda a Dança, com ênfase nos processos cognitivos que se dão no ensino/aprendizagem, principalmente nos temas: aspectos enativos e evolutivos do movimento; Ciências Cognitivas; procedimento metafórico do corpo; corponectividade; Agrega esses temasàs pesquisas na Arte de Movimento de Rudolf Laban. somáticas desenvolvidas por Klauss e Angel Vianna. O evento foi também uma oportunidade para a difusão da obra e do pensamento de Angel e Klauss Vianna ${ }^{11}$, por meio de palestra realizada por Joana Ribeiro Tavares e Marito Olsson-Forsberg, na qual destacou-se o importante papel desempenhado por esses artistas, pedagogos e professores brasileiros Angel e Klauss Vianna - no desenvolvimento de uma proposição original de ensino e investigação do gesto tanto na dança e quanto no teatro (Tavares, 2010).

Em um terceiro momento, em 2016, o mesmo grupo de pesquisadores encontrou-se na cidade de Salvadorpara participar do III Colóquio Internacional de Artes do Movimento: olhares cruzados sobre a capoeira, promovido pelo Programa de Pós-Graduação em Dança da Universidade Federal da Bahia e coordenado pela Prof. ${ }^{a}$ Dr. ${ }^{a}$ Lenira Rengel, em colaboração com a Doutoranda Sandra Santana. A proposição do evento foi de utilizar a especificidade das diferentes abordagens de leitura do gesto em torno de um mesmo objeto de pesquisa: a capoeira. Para isso, as organizadoras convidaram o capoeirista Alex Santo Muniz - Alex de João Pequeno, seu nome de batismo na capoeira- para participar do evento e compartilhar certos conhecimentos sobre a capoeira.Sendo assim, foram propostas oficinas de capoeira angola baiana (Santana, 2017), seguidas de reflexões e discussões sobre dimensões cinéticas, dinâmicas e simbólicas da capoeira. Problematizou-se também as

\footnotetext{
11 Klauss Vianna (1928-1992) e Angel Vianna (1928). Iniciaram a parceria profissional nos anos 1950 e casaram-se em 1955. Rainer Vianna, o único filho do casal, nasceu em 1958 e faleceu em 1995. Foi o primeiro a sistematizar o método desenvolvido pelos pais. Voltaremos a falar mais das abordagens corporais desenvolvidas pelos Vianna. Ver Acervo Klauss Vianna (http://www.klaussvianna.art.br/) e Acervo Angel Vianna (http://www.angelvianna.art.br/).
} 
vantagens e limites na utilização de diferentes sistemas de leitura do gesto aplicados à capoeira.

O evento também tratou da capoeira como possibilidade de gesto brasileiro ou afro-brasileiro. Nessas discussões, ficaram evidentes os contrastes culturais, que tanto potencializam quanto limitam a compreensão de umagestualidade pretensamente marcada como brasileira.

Como destaca Evani Tavares Lima (2002), a origem da capoeira é bastante controversa. No entanto, a grande maioria dos teóricos e praticantes defendem uma teoria única, segundo a qual, a "capoeira foi criada no Brasil por africanos, a partir de uma referência específica, uma espécie de reinvenção de algo já trazido por eles" (Lima, 2002, p. 35). Para além da controvérsia sobre origem da capoeira, a autora destaca a primazia, na capoeira, de uma prática corporal de jogo e luta, com forte utilização de pernas, pés, cabeças e ocasionalmente, braços e mãos como instrumento. Lima (2002) salienta o sentindo de ataque e defesa. Parte da força da capoeira reside na esquiva, a qual, permitindo, a princípio, escapar do golpe do adversário, constitui-se como um movimento que contém em si uma defesa e um ataque, e vice-versa. Outro ponto de destaque dessa prática corporal é a inter-relação do conjunto de elementos que ocorrem simultaneamente tais como o jogo corporal, a luta, a música e o canto.

No âmbito da práticas corporais afro-brasileiras, onde a capoeira está circunscrita, a análise do gesto a partir de uma perspectiva da estética da dança, predominantemente la- baniana, funcional ${ }^{12}$, ou mesmo de uma perspectiva gordardiana ${ }^{13}$, sinaliza o quanto é necessário compreender o gestual da capoeira como uma práticacorporalassociada diretamente a um conjunto de elementos tais como o canto, a música, os instrumentos e os gestos desde uma perspectiva cultural. Mais que isso, o descompasso não ocorre somente em termos conceituais, mas deflagra questionamentos sobre a hierarquia de saberes a partir de perspectivas modernistas, as quaisvislumbram a modernidade como um processo civilizatório decorrente do racionalismo da cultura ocidental (Habermas, 1981). Podemos circunscrevernesse projeto de modernidade certas noções advindas das teorias de análise do movimento, nas suas diferentes acepções e práticas. Como destaca Leda Martins (2003), predomina no Brasil a herança dos arquivos textuais de tradição e de retórica europeia, os quais legitimam uma ideia da natureza do conhecimento centrada na visão e no domínio da linguagem como modos de apreender e delinear o real; para a autora "[a] textualidade dos povos africanos e indígenas, seus repertórios narrativos e poéticos, seus domínios de linguagem e modos de apreender o real e figurar o real, deixados à margem, não ecoaram em nossas letras escritas" (Martins, 2003, p. 64).

12 A análise funcional do movimento refere-se aos estudos, desenvolvidos sobretudo na França, à partir dos anos 1980. Também é denominado Análise Funcional do Corpo no Movimento Dançado (AFCMD). Segundo Roquet (2011), os conhecimentos técnicos que compõem esse sistema baseiam-se na biomecânica do movimento humano, referenciada na anatomia e na fisiologia, buscando questionar e sofisticar o ensino da dança.

130 que denominamos nesse texto de perspectiva godardiana está referida no trabalho pioneiro desenvolvido por Hubert Godard no Departamento de Dança da Universidade de Paris 8. Pesquisadores como Christine Roquet continuam a desenvolver essa abordagem, denominando-a como Abordagem Sistêmica do Gesto Expressivo. Ver Roquet (2011), Roquet (2017), Hinz (2017). 
Há no Brasil e América Latina, saberes tais como a capoeira que escapam a uma análise de retórica europeia, fortemente legitimada no Brasil, sobretudo no ambiente acadêmico das artes. No entanto, o guarda-chuva das práticas culturais, resultado de processos de hibridação ${ }^{14}$, apresenta saberes de uma gnosis e episteme diversas de uma lógica de fundo eurocêntrica. Segundo Martins (2003), são performances do corpo que revelam o que os textos escondem. No nosso caso: um grupo de pesquisadores, em sua maioria brasileiros, brancos, com formação em dança clássica, moderna e contemporânea, tentando circunscrever a prática da capoeira sob o ponto de vista predominante estético da dança. Nesse sentido, acreditamos que práticas tais como a capoeira escapam, burlam e se contrapõem às grades de análise reconhecidas no âmbito da dança contemporânea, tanto no espectro de análise do movimento labaniana ou funcional ou godardiana. Reconhecer essa falésia é algo profícuo, que pode demonstraro quantoas práticas corporais de matriz afro-brasileira e provavelmente outras, como os repertórios indígenas, resistem e destoam do projeto modernista. Tal projetoemerge do mundo ocidental e cultiva uma autoestima etnocêntrica, a qual acaba por abarcar o contexto universitário latino-americano e nós, especialistas em dança. No entanto, em "um mundo fluidamente interconectado", confrontação e diálogo são necessários, afim de contrastar como que nas interculturalidades migratórias, econômicas e midiáticas - ou nos processos de globalização

14 As noções de hibridação ou processos de hibridação de que tratam os estudos do pesquisador argentino Nestor Garcia Canclini (2015), está embasada em uma complexa reflexão para pensar os países da América Latina em uma perspectiva intercultural nas relações que configuram fenômenos da atualidade entre as tradições culturais com a modernidade.
- são oferecidas como fusão e osmose (Canclini, 2015) ${ }^{15}$.

Evidenciaram-se, nesse último encontro em Salvador, as dificuldades de, em tão pouco tempo, fundir reflexão, teoria e prática e produzir algumas assertivas ou sínteses, mesmo que provisórias. Surgiu então, a vontade de organizar uma publicação que difundisse as ideias do grupo e que, ao mesmo tempo, por meio de chamada pública, permitisse dar a conhecer outras abordagens de pesquisadores brasileiros sobre o tema. Assim, propusemos o dossiê Leituras do gesto em artes cênicas, para alavancar as seguintes questões: Como os sistemas de análise do gesto e do movimento abrem-se à diversidade dos modos de encenação do corpo na cena contemporânea? Como as ferramentas propostas por esses sistemas dialogam e contribuem com proposições pedagógicas emancipatórias? Como esses sistemas situam-se em relação aos contextos pós-coloniais, permeados pelo intenso fluxo migratório, pela aceleração das trocas de informação em escala mundial, pela mobilidade cultural, pela desterritorialização e relações assimétricas de poder?

\section{gesto na encruzilhada dos conceitos}

Nos últimos anos, em uma perspectiva de pós-graduação, sobretudo no âmbito do Programa de Pós-Graduação em Artes Cênicas da UFRGS, as pesquisas que abordam o gesto propõem investigações a partir de uma perspectiva reflexiva impulsionada pela análise do

15 Essas assertivas são de ordem pessoal das autoras, considerando que muitas das experiências do último encontro em Salvador ainda estão sendo por nós digeridas e assimiladas. 
fazer artístico, imbricado ou não a práticas pedagógicas ${ }^{16}$.

\section{Temos procurado abordaro estudo do gesto} por meio de diferentes autores, temporalidades e hierarquias conceituais. Buscamos cotejar as produções de pesquisadores universitários e de pesquisadores artistas. , tais como Desse modo, situamosa produção acadêmica de autores que buscam refletir sobre o gesto em perspectivashistórico-cultural, filosóficaou estética como Annie Suquet $(2008,2012)$, Ciane Fernandes (2002, 2014), José Gil (2004), Hubert Godard (1995), Laurance Louppe (1997), Susanne Langer (1980), Sylvie Fortin (1996, 2008) face a perspectivas práticas e a narrativas de artistas como Eva Schul ${ }^{17}$, Eduardo Se-

16 Essa tendência está em sintonia com estudos recentes sobre a pesquisa em artes cênicas no Brasil conforme Santos (2013) e Carreira (2012). Segundo os estudos estatísticos de Santos (2013) grande parte da produção de dissertações e teses produzidas nos programas de pós-graduação no Brasil versa sobre a análise de proposta relacionadas ao fazer artístico. Carreira (2012) também endossa esse ponto de vista quando afirma que cada vez mais as pesquisas em artes cênicas desenvolvidas em âmbito acadêmico no Brasil estreita fortemente laços com a criação artística que circula no país.

17 Eva Schul (1956) coreógrafa e professora, atualmente diretora da Ânima Companhia de Dança sediada em Porto Alegre. Estudou balé em Porto Alegre e nos Estados Unidos, dedicando-se depois ao estudo da dança moderna em Buenos Aires e em Nova Yorque. Suas principais referências nesse campo são Hanya Holm e Alwin Nikolais. Uma das primeiras a trabaIhar com dança moderna e contemporânea no sul do Brasil e a utilizar procedimentos de criação baseados em improvisação e composição coletiva, atuou nos anos 1980 em Curitiba e, a partir dos anos 1990, em Porto Alegre. A coreógrafa foi também responsável por constituir ambientes voltados para a prática e a difusão da dança e da arte contemporânea, como o Espaço Mudança (anos 1970) a Ânima Companhia de Dança e o Coda, centro de terapia corporal e dança (Anos 2000). Destaca-se também uma prolífica e significativa produção coreográfica, que impactou o cenário da dança contemporânea no Brasil. Ver Dantas e Schul, 2012. verino $^{18}$, Carlota Albuquerque ${ }^{19}$, Cecy Franck ${ }^{20}$.

Para entender o gesto na dança, vemos na perspectiva filosófica da estado-unidense Susanne Langer (1980) ${ }^{21}$ um marco primeiro e referencial, seja pela atualidade de sua escrita, datada de 1953, seja pela a busca em determinar a especificidade da dança na força de sua gestualidade, ou ainda pela possibilidade de contraste com autores contemporâneos.

Quanto à especificidade da dança, a autora sustenta que a dança é uma arte independente da música, repudiando a "quase-identidade" na relação entre dança e música. Também a vê comoindependente de "quadros em movimentos", desenho animado, ou estátuas de movimento, o que vincularia a especificidade do gesto na dança à pintura. Repudia também a dança enquanto como uma arte dramática

18 Eduardo Severino (1965) coreógrafo, fundador e diretor da Eduardo Severino Companhia de Dança (2000), em conjunto com Luciano Tavares. Tem formação em dança moderna e contemporânea. Integrou a Ânima Companhia de Dança. O caráter performativo de suas produções tem-se se acentuado nos últimos tempos, a partir de colaborações com diversos artistas de dança, performance e música. Ver Dança em Rede (http://www.spcd.com.br/danca em rede/)

19 Carlota Albuquerque (1957) coreógrafa, com formação em balé e em dança moderna. Em 1981, foi uma das bailarinas fundadoras da Terra Companhia de Dança, em Porto Alegre. Em 1987 fundou a Terpsí Teatro de Dança, onde aprimorou sua poética ligada à dança-teatro. Tem trabalhado em colaboração com diretores teatrais. Desde 2015 é diretora artística e coreógrafa do Canoas Coletivo de Dança, na cidade de Canoas/RS. Ver Dança em Rede (http://www.spcd.com.br/ danca em rede/)

20 Cecy Franck (1924-2000) iniciou os estudos em balé em Porto Alegre já na idade adulta. O encontro com a dança moderna, através das aulas com Nina Verchinina no Rio de Janeiro, nos anos 1960, e na Escola de Martha Graham em Nova lorque, nos anos 1970 , foi decisivo para a carreira dessa professora e coreógrafa. Em 1981 criou o Choreo - Espaço Alternativo de Dança e Grupo Choreo. O Grupo Choreo esteve ativo até 1998, tendo sido um espaço para as criações coreográficas de Cecy Franck e de outros bailarinos do grupo. Ver Dança em Rede (http://www.spcd.com.br/danca em rede/)

210 livro Feeling and Form foi publicado pela primeira vez em 1953. No livro Dança, o enigma do movimento (Dantas, 1999), já utilizávamos as reflexões de Susanne Langer sobre gesto e movimento como definidores da dança como manifestação artística. 
próxima à pantomima. "A pantomima, como padrões de movimento puro, imagens plásticas e formas musicais, é material de dança, algo que pode tornar-se um elemento baléti$\mathrm{co}^{22}$, mas a dança em si é outra coisa" (Langer, 1980, p. 181).

Langer (1980) identifica no gesto o elemento básico da dança: "todo o movimento de dança é gesto, ou um elemento na exibição do gesto [...] O gesto é a abstração básica pela qual a ilusão da dança é efetuada e organizada" (Langer, 1980, p. 182-183). Dentro dessa concepção, o gesto diferencia-se do movimento pelo seu caráter expressivo: os gestos podem constituir-se em sinais ou sintomas de desejos, intenções, expectativas, exigências e sentimentos. Ao mesmo tempo, os gestos podem ser organizados em sistemas logicamente expressivos, como no caso da linguagem dos surdos-mudos. No entanto, para a autora todo gesto é expressivo, dançado ou não. O gesto na vida cotidiana, quer tenha um significado linguístico ou não, é sempre expressivo, seja em virtude de suas formas plásticas (grande, pequeno, etc), seja como o reflexodo estado emocional de quem o executa. Desse modo, como comportamento humano, esse gesto não é arte, é simplesmente movimento vital.

Langer (1980) considera que "a ilusão primária" de uma arte é algo criado como não real, como ilusório, embora existente na imaginação e nos sentidos. A autora exemplifica dizendo que a pintura não é a tinta sobre a parede, mas a ilusão que o pintor cria por meio de tinta sobre ogesso molhado. Sendo o movimento a matéria prima da dança, como ele é transformado, e em quê? Em gesto. Langer (1980) considera que o movimento na dança

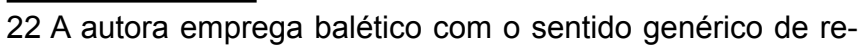
ferente à dança. se torna expressão, tornando-se gesto. A autora sustenta que o caráter gestual da dança é reconhecido pelos dançarinos da modernidade, desde Isadora Duncan, passando por Mary Wigman e Rudolf von Laban, entre outros.

Sendo todo gesto expressivo, o que diferencia o gesto dançado do gesto cotidiano é capacidade de produção de jogos de poderes tornados visíveis, jogos esses que estão na esfera dos poderes virtuais. Esses poderes não podem ser medidos, nem calculados, eles são virtuais, como os poderes misteriosos que dominam a imaginação pré-científica.

Todas as forças que não podem ser cientificamente estabelecidas e medidas devem ser consideradas, do ponto de vista filosófico, como ilusórias; se, portanto, tais forcas parecem ser parte de nossa experiência direta, elas são "virtuais", isto é, semelhanças não-reais... Pois, de maneira bastante estranha, artistas que sustem as teorias mais fantasticamente diversas quanto ao que é a dança - uma música visível, uma sucessão de quadros, uma peça muda - todos reconhecem seu caráter de gesto. Gesto é a abstração básica pela qual a ilusão da dança é efetuada e organizada. (Langer, 1980, p. 182183)

Para autora, não são os sentimentos reais que governam a dança, e sim os sentimentos imaginados; o movimento na dança é real, no entanto o gesto é virtual, tendo sua origem no que Laban chamou movimento-pensamento-sentimento. Aqui surge a contradição de um gesto que é ao mesmo espontâneo e planejado, ou seja, na dança o movimento é real, enquanto o gesto é expressão virtual. A abstração básica da dança é o gesto virtual, que é tanto um fenômeno visível quanto muscular, que pode ser visto, sentido e de certo modo, compartilhado cinestesicamente. 
Outro ponto de destaque no pensamento precursor de Langer (1980) é a compreensão da dança e, consequentemente do gesto dançado, como uma relação de desafio à gravidade. A elaboração da dança passa pelo processo de transformação dos movimentos em gestos virtuais, o que ocorre devido, especialmente, ao movimento trabalhado ritmicamente e à ilusão de conquista da gravidade. Langer reconhece esse poder em diferentes formas de dança, não só na dança considerada cênica ou artista: nas danças sociais, através "das forças magnéticas que unem um grupo", nas danças de casais, pelo poder do ritmo que transporta dois corpos pelo espaço ou nas provocações da esfera do sonho produzidas pelas danças eróticas. Langer vê nesses exemplos um trabalho de elaboração do movimento ruma à ilusão da conquista da gravidade que pelo menos em aparência, disfarça as exigências usuais de esforço do gesto. Para Langer (1980), esse poder virtual é que torna a dança social intrinsicamente arte, ainda que por vezes, possua formas plásticas elementares.

Segundo a autora, o movimento da dança produz, tanto para o bailarino quanto para o espectador, a ilusão de uma conquista da gravidade, a libertação de forças reais que são sentidas como controladoras do corpo. Esse pensamento sobre a especificidade da dança na sua relação com a gravidade é contemporâneo às pesquisas de Laban ${ }^{23}$. Se Langer (1980) não aprofunda o diálogo com Laban, cabe a nós imaginarmos cruzamentos entre as ideias de Langer sobre dança e gravidade e o conceito de peso e seus desdobramentos na

23 Langer (1980), no capítulo Poderes Virtuais, cita Laban em pelo menos duas passagens, através do livro de Laban Die Weltdes Tänzers: Fünf Gedankenreigen, publicado em 1922 na Alemanha. teoria do Esforço ${ }^{24}$ em Laban. Como ressalta Louppe (1997), Laban nos ensina a "aceitar o peso, trabalhar com ele como se trabalha uma matéria viva e produtiva" (p. 97), seja resistindo à força da gravidade e projetando o corpo verticalmente, seja abandonando o corpo à ação gravitacional.

Partindo da noção de Langer (1980) de que dança se realiza pela conquista da gravidade, interessa-nos encontrar os conceitos de organização gravitacional, pré-movimento e musicalidade postural, desenvolvidos por Godard ${ }^{25}$ (1995). Com ele aprendemos que as relações primordiais que uma pessoa estabelece com a gravidade possibilitam um enraizamento no mundo e determinam uma organização do corpo em movimento. $O$ fato de estar de pé pressupõe uma atitude em relação ao peso e à gravidade e uma determinada atividade muscular, mesmo que não se esteja realizando nenhum movimento aparente. A menor movimentação do corpo provoca um reajuste na ação dos músculos antigravitacionais. Godard (1995) denomina este fenômeno de pré-movimento, entendendo-o também como pano de fundo, como contexto onde o movimento é executado. O pré-movimento antecipa cada gesto e anuncia suas qualidades. E traz já um projeto, uma tomada de posição, uma postura em relação ao mundo. Como diz o autor, a cultura, a história de um bailarino, sua maneira de sentir determinada situação, de experimentá-la e de interpretá-la vão induzir uma "musicalidade postural" que acompanhará os gestos intencionalmente executados.

24 Ver Fernandes, 2002.

$25 \mathrm{O}$ artigo seminal de Hubert Godard, Le geste et saperception, foi publicado em francês em 1995 e publicado em português no Brasil em 2003, em tradução de Silvia Soter (Godard, 2003). 
A conquista da gravidade anunciada por Susanne Langer, os princípios teórico-metodológicos desenvolvidos pelo Sistema Laban e as nuances da organização gravitacional enunciadas por Hubert Godard constituem algumas das referências que são deglutidas, digeridas e incorporadas por nós, visando a elaboração de novas sínteses, num gesto antropofágico, que será melhor explicitado a seguir.

\section{— O gesto na combustão das práticas}

Em nossas pesquisas, buscamos cotejar as produções de pesquisadores universitários àquelas de pesquisadores artistas. Acreditamos que além do reconhecimento do legado deixado por grandes pensadores europeus e estado-unidenses como Rudolf Laban, Susanne Langer, Hubert Godard, Laurence Louppe, entre outros, é necessário disseminar o recente pensamento brasileiro desenvolvido por artistas e pesquisadores como Klauss e Angel Vianna e Regina Miranda, entre outros. Já ressaltamos a importância de Regina Miranda no desenvolvimento de estudos e obras artísticas referenciados pelo Sistema Laban-Bartenieff. Destacamos agora o trabalho de Klauss e Angel Vianna. A consciência do movimento é uma das ideias fundadoras do trabalho de Klauss e Angel Vianna, um método de educação do movimento que pode ser considerado como uma prática somática. Atualmente, denominada Conscientização do Movimento e Jogos Corporais, ela inspira uma visão de dança, de movimento, de ensino e de mundo presentes nos cursos de formação profissional, na Graduação em Dança e nos Cursos de Pós-Graduação, oferecidos na Escola e Faculdade An- gel Vianna ${ }^{26}$. A Conscientização do Movimento tem por objetivo permitir ao indivíduo ampliar os conhecimentos do corpo, através da percepção de suas estruturas ósseas, articulares e musculares. Ela visa a liberação de tensões acumuladas, o relaxamento, o contato com o outro, a expressividade e desperta nos praticantes um conhecimento de ordem sensível, motor e cinestésico. O sistema foi desenvolvido por Klauss e Angel Vianna a partir de suas investigações sobre o ensino da dança. Num segundo momento, eles desenvolveram uma pesquisa sobre a função das estruturas corporais (sistemas ósseos, musculares, articulares) no movimento dançado. Posteriormente, foram também influenciados por abordagens somáticas como o método Feldenkrais e a técnica de Alexander. O eixo pedagógico desse sistema está centrado "[...]na experimentação do movimento, no respeito à autonomia do aluno e na extração da teoria a partir do vivido".(Escola e Faculdade Angel Vianna, 2017, s/p.).

Do mesmo modo,é necessário dar voz e visibilidadea precursores tais como Mercedes

26 A Escola de Dança Angel Vianna foi criada em 1983, no Rio de Janeiro, por Angel Vianna. Desde sua criação, oferece cursos livres e duas possibilidades de formação profissional, uma no eixo dança contemporânea e outra no eixo da reeducação do movimento. A partir de 2001, foi criada uma Graduação em Dança, com formação em Licenciatura e Bacharelado. Atualmente, dononima-se Escola e Faculdade Angel Vianna e oferece também Cursos de Pós-Graduação Latu Sensu. 
Batista $^{27}$ e Raimundo Bispo dos Santos ${ }^{28}-$ ou Mestre King - respeitando o desejo de revelar nossa cultura híbrida por meio da dança.

O legado da estética negra no Brasil, como é o caso de Mercedes Batista e de Mestre King, dentre outros artistas, nos permite repensar aspectos do gesto brasileiro para além das noções de autenticidade e de identidade, afastando-nos de qualquer noção de pureza cultural. Trata-se de reconhecer como as narrativas recentes do gesto brasileiro, que seafirmamcomo arte a partir da segunda metade do século XX, podem ser revisitadas pelo olhar contemporâneo, impregnado por recentes epistemologias e tecnologias. Estamos conscientes de que habitamos um país periférico e de que vivemos entre uma modernidade precária, sinuosa e inacabada e uma pós-modernidade que acentua as relações assimétricas de poder. Por isso, interessa-nos problematizar o gesto entrecruzando abordagens teórico-metodológicas europeias, estado-unidenses e brasileiras, saberes oriundos das tradições

27 Nascida em 1930, no estado do Rio de Janeiro, mudou-se para a capital ainda pequena. Fez formação em balé na Escola de Bailado do Teatro Municipal do Rio de Janeiro e tornou-se a primeira bailarina negra do Teatro Municipal do Rio de Janeiro. Integra o Teatro Experimental do Negro. Após as apresentações no Rio de Janeiro da Companhia de Dança de Katherine Durham, em 1951, Mercedes Baptista obtém uma bolsa de estudos e vai para Nova York estudar com a coreógrafa. Duham mesclou os princípios da dança moderna estado-unidense aos das danças afro-caribenhas. Um ano depois, no seu retorno, reúne um grupo de artistas negros e inicia o trabalho que viria a gerar o Balé Folclórico Mercedes Baptista e gestando o que seria denominado posteriormente de Dança Afro. Segundo Monteiro (2011), a dança afro de Baptista configurou-se "como uma prática e um repertório em ruptura com o balé clássico e completamente identificado com os novos parâmetros da dança moderna, tendo como referência a tradição africana tal qual se configurava no Brasil” (p. 10).

28 Nascido em 1943, em Santa Inês/Bahia, com formação inicial em capoeira, foi o primeiro homem e negro a se formar no Curso de Graduação em Dança da Universidade Federal da Bahia. Coreógrafo e professor, seu trabalho de dança afro-brasileira foi se delineando na fusão entre danças dos terreiros de candomblé com técnicas de dança moderna e tornou-se referência. Ver Oliveira, 2008. africanas, indígenas e de outros povos não europeus, práticas de hibridação e mestiçagem tão caras às artes latino-americanas, avanços tecnológicos, culturas massivas e midiáticas

O reconhecimento da verticalidade de pensamentos ocidentais seminais para os estudos em dança, relacionados a saberes advindos das danças, dos rituais edas práticas performáticas de matriz africana ou indígena,ou mesmo da dança contemporânea brasileira resta como uma difícil encruzilhada a ser atravessada (Martins, 2003). Dialogar com todo esse espectro de demandas frente à combustãode questões emergentes provenientes das práticas artísticas pós-modernas, requer escolhas, embates e reconciliações.

Como compreender, captar, analisar e performar o gesto frente a questões espistemológicas, interdisciplinares e interculturais? Esse desafio merece ser desenrolado feito o fio de Aridne, labirintos que cada pesquisador pode ou deve percorrer à sua maneira. $\mathrm{O}$ encontro de um grupo em sua maioria brasileiros com a pesquisadora Christine Roquet, permite-nos uma troca profícua de pensamentos e vivências interculturais entre o exercício crítico do pensamento francês não somente de pensar a dança, mas o corpo, frente a nós pesquisadores latino-americanose nossa adaptabilidade camaleônica de dialogar e buscar a solidificação da pesquisa do gesto num espaço nacional, latino, cosmopolita e internacional. Parece importante no contraste com a vasta cultura francófona que Christine Roquet nos proporciona e representa, reconhecer e descortinar nosso próprio e recente legado daqueles que como Mercedes Batista, Angel e Klauss Vianna, Cecy Franck e Eva Schul, entre outros, buscaram e buscam através de uma prática e reflexão somática/cinestésica do gesto acom- 
panhada de questões em torno da expressividade e da arte. Ainda, difundir e compreender esses e outros artistas/pesquisadores que estão atuantes na busca de apreensões do gestoreferenciado em matrizes brasileiras, tais como Mestre King, Antônio Nóbrega ${ }^{29}$, Luiz de $\mathrm{Abreu}^{30}$, para nos alimentarmosde nossa própria cultura.

Há na cultura brasileira, uma dança reconhecida através de um gestochamado de umbigada, um bater-se ou um encontrar-se de umbigos que serve como convite para entrar ou sair da dança. Com as nossas roupas curtas, como metáfora da nossa entrada recente no campo dos estudos em dança, frente ao legado de conhecimento europeu e norte-americano, resta praticar a umbigada entrenós mesmos e com os outros e outros. A umbigada deu origem ao samba, nosso maior produto de exportação de dança brasileira, clichê e sofisticação da arte e da cultura brasileiras. O samba permite a troca e o swing com os estrangeiros, estrangeiros esses que, às vezes, estão

\footnotetext{
29 Antônio Nóbrega (1952) nasceu em Recife. É violinista desde criança. No final dos anos 1960 passou a integrar como instrumentista e compositor, o Quinteto Armorial - grupo precursor na criação de uma música de câmara brasileira de raízes populares. A partir dos anos 1970, percorreu quase todo o Brasil estudando as manifestações populares, aprendendo cantos, toques instrumentais, danças, modos de representar dos brincantes, folgazões e demais artistas populares. Desde 1975 começou a desenvolver um estilo próprio de concepção em artes cênicas, dança e música e criou inúmeros espetáculos nos quais desenvolveu suas concepções. Juntamente com sua mulher, Rosane Almeida, idealizou e dirige, em São Paulo, o Instituto Brincante local de cursos, oficinas, mostras e encontros que procuram apresentar aos próprios brasileiros um Brasil ainda pouco conhecido.
}

30 O primeiro contato de Luiz de Abreu com dança ocorre na década de 1960, nos terreiros de umbanda em Araguari, onde interpreta várias entidades do culto. Em 1986 muda-se para Belo Horizonte e trabalha na Companhia de Dança de Minas Gerais e Companhia de Dança Primeiro Ato. Nos anos 1990, começa a carreira solo em São Paulo, e dança com Ivaldo Bertazzo e Mim Tanaka. Em 2004 estreia o solo O samba do crioulo doido, referência como um trabalho coreográfico que expõe modos de estereotipar e desconstruir estereótipos sobre o corpo negro e brasileiro. entre nós mesmos. Nada é consenso em um mundo pretensamente globalizado, há muitos brasileiros que não tem samba no pé. Entre a umbigada e dança da corte européia, muitas trocas podem ser profícuas. A busca desse pequeno grupo franco-brasileiro cosmopolita frequentado por pesquisadores e artistas que se agregam e desagregam a um pequeno núcleo estável, nos faz deslizar, reconhecer e confrontar além das tradições e modernidades da dança, do movimento e do gesto. O deslizamentotambém está entre o culto, o popular e o massivo/midiático, o somático e o estético, e outras tantas polarizações e espectros que nos permite pensar o corpo dançante em meio a instabilidades, poros, lacunas, obliquidades, enfim, o gesto como enigma e mistério na combustão da pós-modernidade.

Ensaiamos então, a exemplo de Oswald de Andrade (Andrade, 1976) e de tantos outros artistas antropófagos brasileiros, o gesto antropofágico. A Antropofagia, a partir de $O$ manifesto antropófago, publicado pela primeira vez em 1928 retoma as ideias de canibalismo ritual praticados pelos índios da tribo Tupinambá e propõe a ação antropofágica: devorar a cultura estrangeira, digeri-la e assimilá-la seletivamente para restaurar seu próprio patrimônio cultural. A Antropofagia reivindica e se apropria dos estereótipos do Novo Mundo - o exotismo, o barbarismo, o canibalismo - com ironia e sarcasmo. Engajar-se com esses estereótipos é também um modo de admitir a diferença, reconhecer a fatalidade de ser colonizado e as possibilidades de lidar com isso. As metáforas de consumo de carne humana são talvez violentas. Mas elas podem operar como estratégias de produção artística, cultural e política em países periféricos como o Brasil, sendo menos demagógica e consensual que as proposições 
de interculturalismo, multiculturalismo, hibridação, justamente por oferecer experiências de violências transformadas (Dantas, 2008). Gestos antropofágicos são noções a serem melhor desenvolvidas, afinadas em práticas de devoração, digestão, indigestão, assimilação, realização de novas sínteses e reconhecimento do gesto do outro em sua diferença virtuosa e corajosa.

\section{Referências}

ANDRADE, Oswald. O manifesto antropófago. In TELES, Gilberto Mendonça. Vanguarda européia e modernismo brasileiro: apresentação e crítica dos principais manifestos vanguardistas. Petrópolis: Vozes; Brasília: INL, 1976.

BARTENIEFF, Irmgard; LEWIS, Doris. Body Movement: coping with the environment. Langhorne: Gordon \& Breach, 1997.

CANCLINI,Néstor García. Culturas híbridas. São Paulo: Edusp, 2015.

DANTAS, Mônica. Dança, o enigma do movimento. Porto Alegre: Editora da UFRGS, 1999.

DANTAS, Mônica Fagundes. Cedontsontfaitslescorpsanthropophages:laparticipationdesdanseurs à lamiseenceuvrechorégraphiquecommefacteur de construction de corpsdansants chez deuxchorégraphesbrésiliennes. 2008. 434 f. Tese (Doutorado) - Curso de Études Et Pratiques Des Arts, Université Du Québec à Montréal, Montreal, 2008. Disponível em: <http://hdl.handle.net/10183/15587>. Acesso em: 03 nov. 2017.
DANTAS, Mônica Fagundes;SCHUL, Eva. Apontamentos para uma reflexão sobre dança contemporânea ao Sul do Brasil a partir do Projeto Dar carne à memória. In: MEYER, Sandra; XAVIER, Jussara; TORRES, Vera. (Org.). Histórias da Dança. Coleção Dança Cênica. Florianópolis: Editora da UDESC, 2012, v. 2, p. 100-120.

CARREIRA, André. Pesquisa como construção do teatro. In Pesquisas em artes cênicas: textos e temas, (org) TELLES, Narcíso. Rio de Janeiro, 2012.

CARREIRA, André.; TORRES, Walter Lima; BIÃO, Armindo (Org). Da cena Contemporânea. Porto Alegre: ABRACE, 2012.

FERNANDES, Ciane. O corpo em movimento: o Sistema Laban/Bartenieff na formação e pesquisa em Artes Cênicas. São Paulo: Annablume, 2002.

FERNANDES, Ciane. Pesquisa somático-performativa: sintonia, sensibilidade, integração. Art Research Journal, v. 1, n.2, p. 76-95, 2014.

FORTIN, Sylvie. L'éducation somatique: nouvel ingrédient de la formation pratique en danse. Nouvelles de danse, n. 28, p. 15-30, 1996.

FORTIN, Sylvie. Danse et santé: du corps intime au corps social. (Org.). Montréal: Presses de l'Université du Québec, 2008.

GIL, José. Movimento total: o corpo e a dança. São Paulo: Iluminuras, 2004. 
GODARD, Hubert. Le geste et sa perception. In: MICHEL, Marcelle; GINOT, Isabelle (Org.). La Danse au XXe siècle. Paris: Bordas, 1995. p. 224-229.

GODARD, Hubert. Gesto e Percepção. In PEREIRA, Roberto; SOTER, Silvia. Lições de Dança 3. Rio de Janeiro: UniverCidade, 2013, p. 11-35.

HABERMAS, Jurgen. La modernidad: un proyecto inacabado. Barcelona: Ediciones Península, 1988.

HINZ, Guilherme. Pensar o gesto dançado: entrevista com Christine Roquet. Cena n. 22, 2017 (no prelo).

LANGER, Susanne K. Sentimento e Forma. São Paulo: Editora Perspectiva, 1980.

LIMA, Evani Tavares. Capoeira Angola como treinamento para o ator. Dissertação de mestrado. Salvador, UFBA, 2002.

LOUPPE, Laurence. Poétique de la danse contemporaine. Bruxelles: Contredanse, 1997.

MARTINS, Leda. Performances da Oralitura: corpo, lugar da memória. In Letra, n. 53. Universidade Federal de Santa Maria, junho, 2003, p. 63-80.

MIRANDA, Regina. O movimento expressivo. Rio de Janeiro: Funarte, 1980.

MIRANDA, Regina. Corpo-espaço: aspectos de uma geofilosofia do corpo em movimento. Rio de Janeiro: 7Letras, 2008.
MONTEIRO, Marianna. Dança Afro: Uma Dança Moderna Brasileira. In: NORA, Sigrid e SPANGHERO, Maíra. (Org.). Húmus 4. Caxias do Sul: Lorigraf, 2011, p. 51-59.

OLIVEIRA, Debora Féraz de. A construção da identidade negra através da dança Afro Brasileira: a história de Mestre King. Rio de Janeiro: MINC, 2008.Disponível em http://www.bn.br/ portal/arquivos/pdf/debora ferraz.pdf. Acesso em 22 mar. 2017.

RENGEL, Lenira. Os temas de movimento de Rudolf Laban: modos de aplicação e referências. São Paulo, Annablume, 2008.

ROQUET, Christine. Da análise do movimento à abordagem sistêmica do gesto expressivo. O Percevejo Online, v. 3, n. 1, 2011. Disponível em http://www.seer.unirio.br/index.php/opercevejoonline/article/view/1784/1447. Acesso em 02 mar. 2017.

ROQUET, Christine. Ler o gesto. Cena n. 22, 2017 (no prelo).

SÃO PAULO COMPANHIA DE DANÇA (São Paulo). Dança em Rede.Disponível em: < http:// www.spcd.com.br/danca em rede/. Acesso em: 05 abr. 2017.

SANTOS, Eleonora Campos da Matta. Artes Cênicas no Brasil. Pelotas: Ed. Universitária/ UfPel, 2013.

SUQUET, Annie. O corpo dançante: um laboratório da percepção. In CORBIN, Alain; COURTINE, Jacques; VIGARELLO, Georges. (Org.). História do Corpo 3. As mutações do olhar. Rio de Janeiro: Editora Vozes, 2008, p. 509-540. 
SUQUET, A. L'éveildesmodernités. Paris: Centre national de ladanse/Pantin, 2012.

TAVARES, Joana Ribeiro da Silva. Klauss Vianna, do coreógrafo ao diretor. São Paulo: Annablume, 2010.

VIANNA, Angel. Acervo Angel Vianna. Disponível em: http://www.angelvianna.art.br. Acesso em: 11 mar. 2017

VIANNA, Angel. Acervo Klauss Vianna. Disponível em: http://www.klaussvianna.art.br. Acesso em: 15 mar. 2017.

Recebido: 01/07/2017 Aprovado: 07/07/2017 